\title{
Restructuring Outsourcing: Classification and Methodical Approach to Evaluating Expediency and Economic Effect
}

\author{
Il'nur Ildusovich Farkhoutdinov ${ }^{1} \&$ Aleksei Gennadevich Isavnin ${ }^{1}$ \\ ${ }^{1}$ Economic Department, Kazan Federal University, Russia \\ Correspondence: Il'nur Ildusovich Farkhoutdinov, Ph.D., associate professor of chair of business informatics and \\ mathematical methods in economics, economic department of Kazan Federal University, Russia. E-mail: \\ ilnour1986@inbox.ru
}

Received: October 9, 2020

Accepted: December 2, 2020

Online Published: January 14, 2021

doi:10.5430/ijfr.v12n2p274

URL: https://doi.org/10.5430/ijfr.v12n2p274

\begin{abstract}
A large part of a country's national production is the result of the efforts and performance of organizations and institutions that are engaged in the production of goods and services. These organizations or institutions that operate in various forms of government, private and cooperative and in various sectors of industry, agriculture and services are called economic enterprises or manufacturing enterprises. Among the strategies that have played a role in economic development in recent decades and have led to its expansion; It is the creation of small and medium-sized enterprises that in most countries (developed and developing) the tendency to this type of enterprises has increased. Medium-sized enterprises, in terms of their significant role in job creation, competitiveness, innovation and organizational and economic development, are considered as drivers and engines of economic growth and are one of the most important priorities in economic development programs. In the modern world, classification and methodical approach to evaluating expediency and economic effect has a critical role. In this paper, we consider the restructuring of Russian industrial enterprises through the use of industrial outsourcing. An approach to the classification of restructuring industrial outsourcing is proposed, and a method of assessing the feasibility and economic effect of the usage of this type of outsourcing is developed.
\end{abstract}

Keywords: restructuring outsourcing, minimal outsourcing, effective outsourcing, radical outsourcing, production capacity, break-even point, outsourcing classification, feasibility assessment, economic impact assessment, economic cycles

\section{Introduction}

The complex and wide-ranging developments of the last few decades have led various societies to try to prepare themselves more and more for the acceptance of the change. In the past decades, the formation of large companies and keeping them active and, consequently, the governmentalization of most organizations; It was seen as an economic advantage, and it was argued that the larger these companies were, the more dynamic and powerful the economy would be. Although this thinking flourished over several decades and led to the emergence of giant corporations, recent developments, especially demographic pressures, more complex management and decision-making processes, and the need for instant decision-making have led to change. It has become fundamental in the structure of these giant organizations (Jiangpo, 2008; Christina et al., 2014; HassanOMER et al., 2020).

Therefore, today, the formation and operation of small and medium-sized enterprises are considered as a strategic approach in many countries, especially developing countries, and in recent years, the importance and role of these enterprises in industrialized and developing countries. Has been on the rise. Small and medium industries are considered as a suitable platform for creating competitive and capable industries, and in most countries, appropriate policy-making for these industries has been emphasized, and their importance in the economy of countries in terms of number is such that a high percentage of the total number of industries make (Bartlett, W., \& Bukvič, 2001; Solaimani et al., 2018). For example, approximately 19 million units (equivalent to $99.8 \%$ of existing businesses) in the EU are small and medium-sized businesses. While in the United States, it is over 99\%, and in Japan, the same figure is observed. Small and medium enterprises play a major role in the economy and employment and are the mainstay of the economy in the industrialization process. This sector is very important and necessary for the transition economies of developing countries. 95\% of industrial units in India are small industries, which account for 
$40 \%$ of production and $35 \%$ of exports. The share of small and medium businesses in the Iranian economy in terms of numbers is over 95\% (Kotrlik et al., 2001; Alexander et al., 2013; Asma et al., 2017; Widayani et al., 2020).

Today, in most countries of the world, small and medium industries are playing a role in various aspects of social, industrial production and the invention of new methods that will lead to technological changes and increase production capacity. And sometimes these units are the cradle of transformation and innovation and the invention of new technologies. On the other hand, the creation of these industries, the need to change the role of government, empower the private sector, competitiveness of the economy and interaction with the rules of globalization, and given the significant exports of these enterprises, play an effective role in economic development; Today, almost all countries are trying to develop these enterprises in their industrial structure (Onn, 1990; Visvanathan \& Kumar, 1999; Poncotoyo, 2018; XuHamdani et al., 2019).

The most important fundamental and infrastructural factor in designing a country's economic development policies is determining the role of the public and private sectors in the process of economic transformation. Therefore, before selecting various development policies, the framework of these areas should be determined, and the weight of each sector in various economic activities should be determined. Determining the weight of each sector in any activity depends on various internal and external factors, the most important of which are the prevailing ideology and goals of the government, world economic conditions and its polarization, capacity and capabilities of the public and private sectors and the degree of economic development. Therefore, economic, financial, trade, energy, agricultural, industrial, etc., policies must be designed to provide development that is economically, socially, and ecologically sustainable. Thus, policies of downsizing and restructuring, changes in management processes, and especially the promotion of entrepreneurship and development in the age of globalization, have accelerated the creation of small and medium-sized entrepreneurial institutions. It must be said that such units are an integral part of the process of change; Because they are looking for competition and are changing the overall structure of the market (Seth et al., 2018).

Due to the high flexibility that small and medium-sized companies have, they become more entrepreneurial and innovative. In addition, they can better adapt to new environmental conditions and react to economic and social factors. These firms attract countries and employ skilled labour, and because they can be created with less capital than large corporations, the amount of employment they create is greater than that of large corporations and corporations. Another noteworthy point is that productivity in small and medium industries is higher than large industries; Because small industries are managed by individuals and are located in industrial towns and cities, which if we pathology and strengthen it, we will achieve results faster than large industries (Jauhari et al., 2020).

It is also more cost-effective to promote small industries. Therefore, different countries pay special attention to the formation of these enterprises. And since all of these characteristics apply in developing countries, this type of industry is more welcomed in these countries. These enterprises are defined as the foundation of creative activities and participation in the development of entrepreneurial production talents, and this is what is the foundation of future industrial development. On the other hand, encouraging these companies to participate in the economy is considered as a reason for increasing competition and adding flexibility to the economic structure. The nature of small and medium enterprises is different, and they can be established for any kind of activity in different urban and rural areas and be considered as the main basis of the economy. Therefore, creating and supporting small and medium enterprises is one of the main priorities in the economic development programs of many developed and developing countries (Szromek \& Naramski, 2019).

Today, the use of sourcing models to optimize the activities of enterprises is one of the most popular management tools (Simmonds \& Gibson, 2008; Wu \& Park, 2009). In Russia, the most common models are outsourcing and models sourcing's maneuver. Given the characteristics of domestic industry and the cyclical development of a market economy, the main reason for resorting to the restructuring of production facilities through the use of outsourcing and sourcing's maneuver is to reduce the breakeven level of the enterprise. In other words, sourcing models, when properly applied, can increase production flexibility (Okpala, 2019).

However, in addition to the downturns in economic growth, it is necessary to take into account the ups as well, since having sufficient production capacities, it is possible to satisfy the growing volume of orders for manufactured products without restrictions, which, without a doubt, positively affects the financial condition of the company (Dunn, 1999; Isavnin \& Farkhoutdinov, 2014; Ardiana, 2020). It follows that the optimization of the enterprise through the use of sourcing models should, on the one hand, ensure a low break-even level, and on the other hand, provide an opportunity to increase production volumes to the required level. In this regard, the issue of developing methodological support, which allows the correct assessment of the feasibility and economic effect of the usage of 
the sourcing model becomes relevant. The purpose of this work is to develop an approach for the classification of restructuring production outsourcing and a methodology for evaluating the feasibility and economic effect of using this type of outsourcing in the enterprise. In other words, we consider the restructuring of Russian industrial enterprises through the use of industrial outsourcing. An approach to the classification of restructuring industrial outsourcing is proposed, and a method of assessing the feasibility and economic effect of the usage of this type of outsourcing is developed.

\section{Methods}

\subsection{Restructuring Production Outsourcing}

Restructuring is the act of transferring some of an organization's internal activities and delegating decision-making power to an outside supplier under a contract. In fact, in practice, in outsourcing, not only the activities are transferred, but also the factors of production and the right to decide in most cases. In the past, outsourcing was used when organizations could not perform well. They were weak in competition, had a reduced capacity, faced financial difficulties, or were technologically backward and failed. Today, highly successful organizations also use this tool to restructure their organizations. Managers of these organizations understand as a vital issue that it is necessary to create key capabilities to meet customer needs and should strive to do so. The main reasons for outsourcing are:

- Increase effectiveness by focusing on what the organization is best at doing.

- Acquiring specializations, skills, and technologies that were not previously available.

- Get new and innovative ideas

- Reduce investment in assets and make better use of them for other purposes

- Gain market share and business opportunities through a network of providers

- Change fixed costs to variable costs

Restructuring production outsourcing is the most popular sourcing model in Russia. This means that the company sells non-core assets by other companies, and they can involve all aspects of outsourcing (Belcourt, 2006), or the output of assets in a subsidiary or joint venture, that is, the use of so-called internal outsourcing (Kotliarov, 2012). To date, a large number of approaches concerning the classification of restructuring production outsourcing are presented in scientific and practical literature. Figure 1 shows one of the most common approaches.

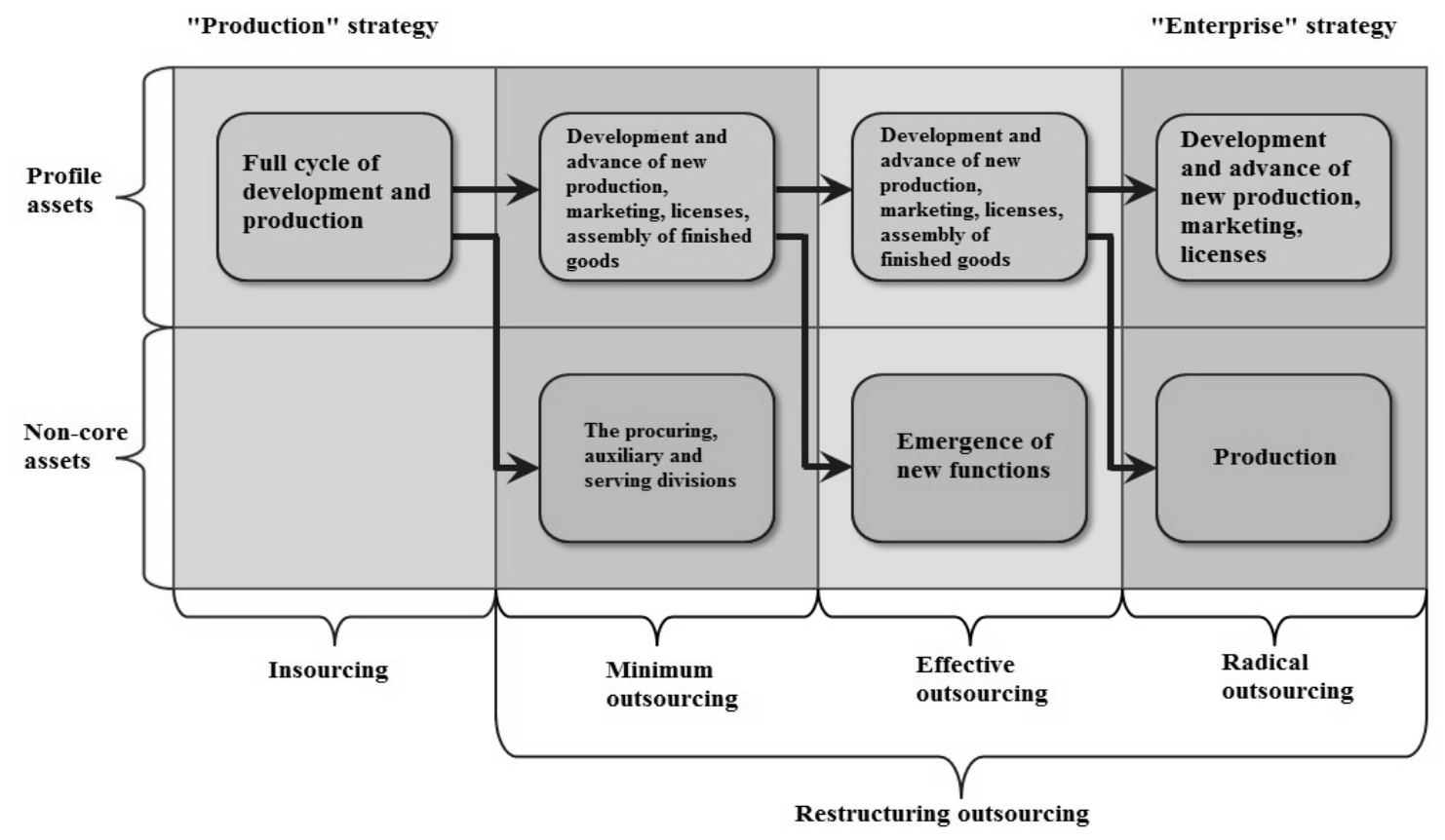

Figure 1. Restructuring production outsourcing 
Another interesting approach to the classification of production outsourcing characterized by the restructuring of the enterprise's production facilities is proposed by Makhmutov (2014), which is based on IDEF0 (Makhmutov, 2014). In particular, these economists classify outsourcing into the following groups:

1. Outsourcing of the input (output) of the process, which is understood as the acquisition, receipt or borrowing from external sources of material products, which are subsequently converted to a finished product during the implementation of the process. For example, blanks or components.

2. Outsourcing of process control, which means borrowing control mechanisms from third-party organizations. For example, a technological process developed by a third-party economic entity.

3. Outsourcing of process implementation mechanisms, this is understood as the use of external process implementation mechanisms. For instance, equipment that is on the balance sheet of another company.

The approaches to the classification of restructuring production outsourcing presented in the scientific and practical literature are based on certain criteria. However, these available approaches, including those discussed above, do not characterize outsourcing from the point of view of the ultimate goal for which this sourcing model was applied at the enterprise. In this regard, there is a need to develop such an approach.

\subsection{Cyclical Economic Development}

The approach proposed in this paper to the classification of restructuring production outsourcing is based on the cyclical nature of economic development. It was previously noted that the restructuring of production facilities through the usage of outsourcing is a particularly popular tool to increase the competitiveness of companies in Russia. For example, restructuring outsourcing has been actively used and is being applied by such companies as "GAZ Group", "OMZ", "RUSAL" and other domestic industry companies (Tsukerman \& Kozlov, 2018). In this case, one of the main tasks of restructuring outsourcing is to reduce the breakeven point indicator, which helps to increase the stability of enterprises in economic downturn periods.

Outsourcing has proven itself as a tool to increase the firm's resistance to negative external factors in North America, in particular, in the USA and Canada. A salient example is the American automotive industry, which is much more sensitive to fluctuations in economic activity than European automotive industry (Figure 2) according to an analysis conducted by "PACCAR Inc." (http://www.paccar.com).

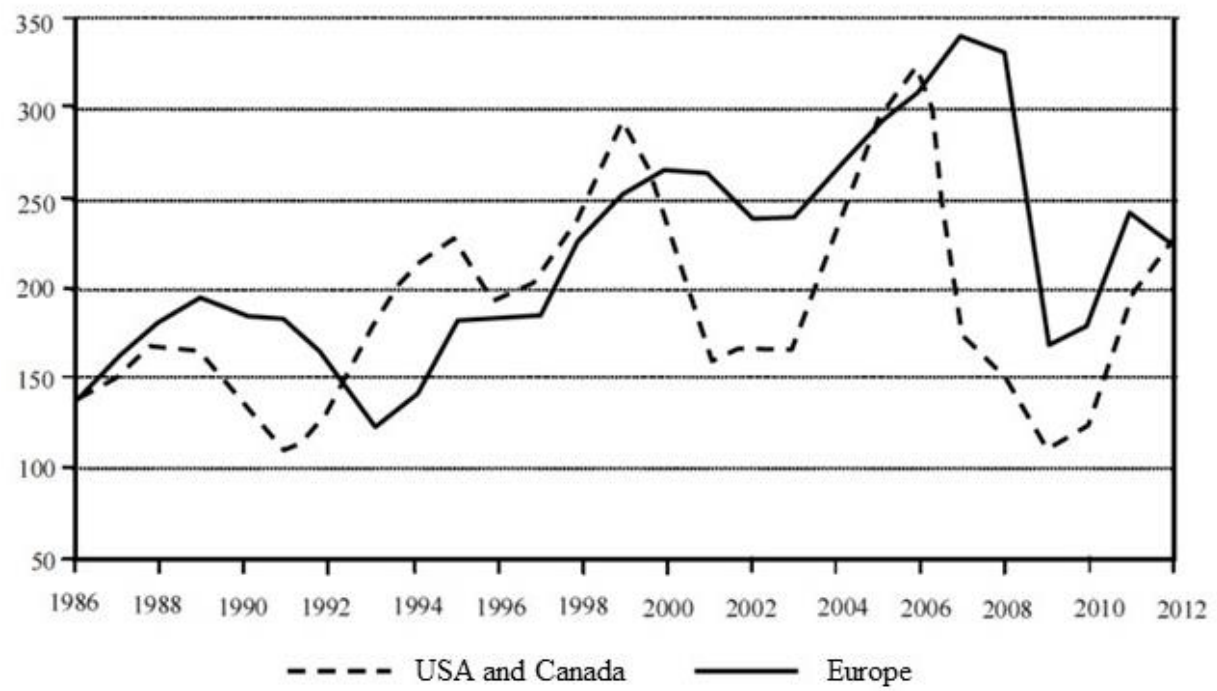

Figure 2. Cycling of the truck market in Europe and America in 1986-2012, thousand units

During economic activity downturns, the automobile markets of the USA and Canada "sink" deeper than the European market. Hence, American automakers have a relatively low break-even level, which was achieved by restructuring production facilities through production outsourcing utilization. In particular, car manufacturers in the USA and Canada mainly concentrate on the production of cabs, spar and truck assembly, while the production of the 
remaining truck components is outsourced. For example, the American company known as "Peterbilt Motors Company" offers the buyer an engine for the selected truck from at least two suppliers - "Paccar Inc." and "Cummins Inc." (Isavnin \& Farkhoutdinov, 2013) It should also be noted that truck frames in the USA are standardized in width, which is why the axles and axles of American auto parts manufacturers such as "Dana Inc." and "Meritor Inc." are applicable to all American trucks (Isavnin \& Farkhoutdinov, 2013).

Also, at present, scientific and practical literature presents works that demonstrate mechanisms for reducing an enterprise breakeven level using restructuring outsourcing, on the basis of which the authors propose a variety of tools for optimizing production and methods for assessing the economic effect of applying the sourcing model (Isavnin \& Farkhoutdinov, 2013).

Another important task of restructuring outsourcing, in addition to reducing the break-even point, is to increase the enterprise's production capacity, which, as a rule, is achieved by optimizing business processes and, as a result, eliminating bottlenecks (Farkhoutdinov \& Isavnin, 2017) and attracting additional capacity of the outsourcer (http://www.mirkin.ru). Outsourcing can also be insured in case of their own production capacities failure (http://www.mirkin.ru).

Thus, having examined the main motives for restructuring production outsourcing usage, we can conclude that this sourcing model increases the enterprise's flexibility, in particular, increases its resistance to decline in sales volumes and makes it possible to satisfy the sharply increased volume of demand for products during the period of economic recovery. These advantages of outsourcing are closely related to the cyclical nature of economic development.

\section{Results and Discussion}

Moving towards small and medium-sized businesses is optimal and profitable, and on the other hand, it is necessary to achieve the goals of sustainable development. These industries affect the global economy in at least four ways: entrepreneurship, innovation and technological change, industry dynamics, and job creation and income. These characteristics have led to increased attention to the development and expansion of these industries for governments in various countries, especially developing countries. About $90 \%$ of the world's industrial units are small and small industries, and more than $39 \%$ of GDP is related to these industries. In previous decades, economists looked more at large industries as the engine of economic growth, job creation, and so on. But today, a fundamental change in economic activities is taking place with the distance from large industries and the activation of small and medium industries. It can be concluded that the development of small and medium industries can be considered as a suitable strategy for these countries. These industries can improve poverty by increasing poverty, increasing income, creating more job opportunities, accumulating capital through increasing productivity, improving productivity in the rural sector, and so on. Countries help from economic and social dimensions and have accelerated the economic growth of these countries. If special attention is paid to the performance of this sector of industries, and the necessary support is provided to them, their speed will increase in the direction of growth and development.

\subsection{Key Assumptions Made in Developing Approaches}

When developing approaches to the classification of restructuring production outsourcing and evaluating the feasibility and economic effect of using this type of outsourcing at the enterprise, the following assumptions were made:

1. In the cyclical nature study of economic development, the object of analysis is the dynamics of all macroeconomic indicators, but the most common is the analysis of economic cycles on the example of fluctuations in GDP. However, in this paper, cyclicality is characterized by the volume of product consumption.

2. The economic cycles adopted in work do not differ from each other in duration, intensity, or other parameters; thus, the trend line has neither a positive nor a negative slope.

3. The duration and frequency of the considered economic cycles are abstract and given.

4. The object of the study is the company; therefore, the cyclical nature of this work is presented in the size of one company. In other words, the considered economic cycles are conditionally distributed on one specific firm.

\subsection{Outsourcing Classification Approach}

Based on the aforementioned assumptions, we visualize the considered economic cycles and the company's sales volumes before applying restructuring production outsourcing (Figure 3). 


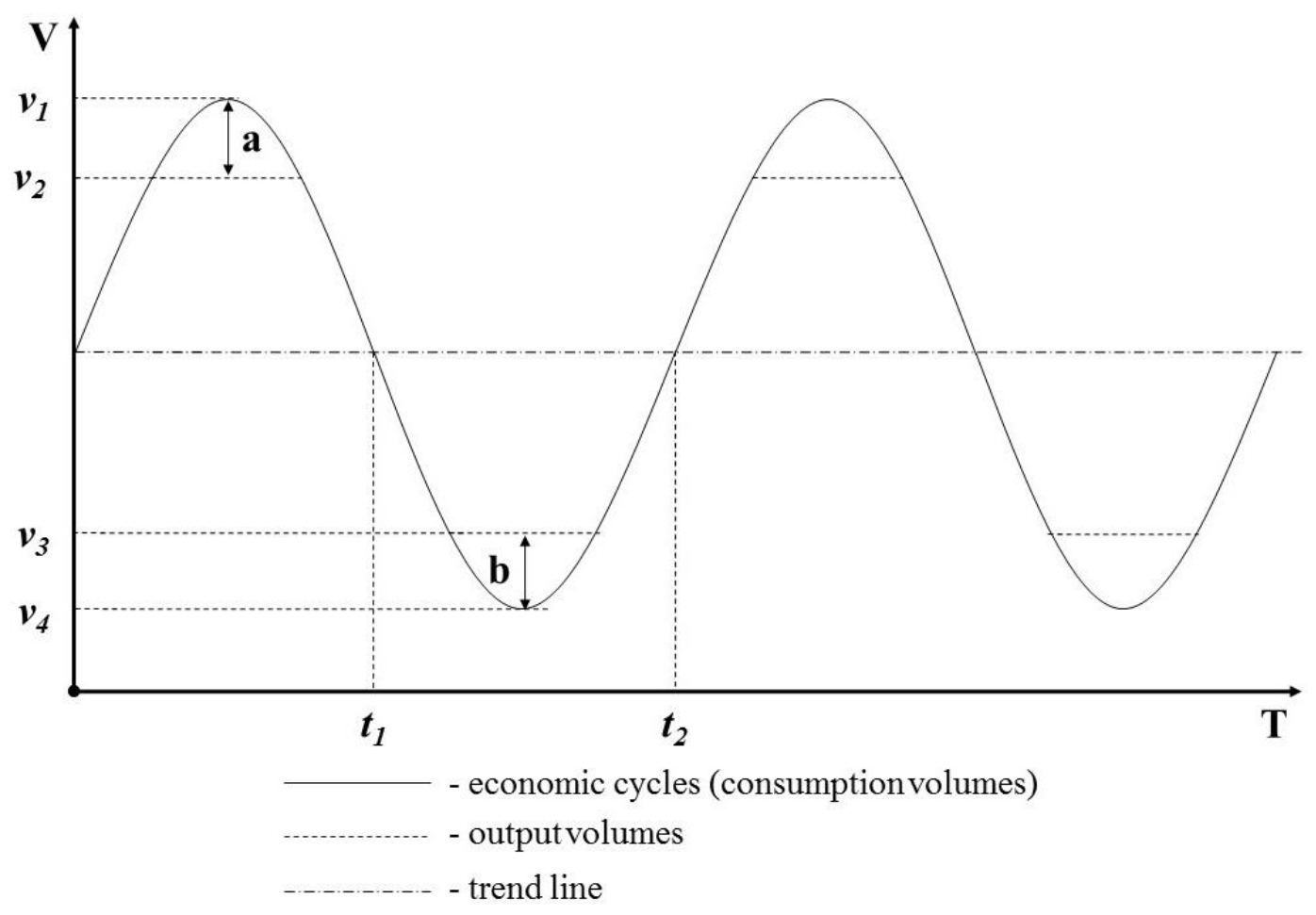

Figure 3. Economic cycles and volumes of sales of an enterprise before outsourcing

Note: $v_{1}$ - volume of consumption of products manufactured by the enterprise at the peak of the economic cycle; $v_{2}$ - the enterprise's production capacity before outsourcing; $v_{3}$ - the enterprise's breakeven point before outsourcing; $v_{4}$ - products' volume of consumption manufactured by the enterprise at the bottom of the economic cycle.

Figure 3 reads as follows:

- At the peak of economic development, products' volume of consumption exceeds the production capacity of the enterprise; accordingly, the company cannot fully satisfy the increased demand and does not receive potential profit;

- At the bottom of the economic cycle, consumption is significantly lower than the breakeven level of the enterprise, respectively, the company suffers losses.

The situation shown in Figure 3 is quite typical for Russian industry, which pushes domestic manufacturers to switch to outsourcing and optimize production facilities. An example is the company "Irbit Motorcycle Plant", which sold forge and machine shops and purchases components for motorcycles from outsourcers, and company "KAMAZ", which outsourced gearbox production (Isavnin \& Farkhoutdinov, 2012a,b).

Figure 3 depicts for what purpose restructuring production outsourcing should be applied - to increase production capacity and reduce the breakeven level of the enterprise, that is:

$$
\left\{\begin{array}{l}
v_{2} \rightarrow v_{1} \\
v_{3} \rightarrow v_{4}
\end{array}\right.
$$

Let us present the following approach to the restructuring production outsourcing classification:

1. $a>0$ и $b>0$. The use of outsourcing is equally aimed at both increasing production capacity and reducing the breakeven point of the enterprise. We call this model "symmetric outsourcing".

2. $a>0$ и $b \approx 0$. The use of outsourcing is aimed at increasing the production capacity of the enterprise. We call this model "enhanced outsourcing".

3. $a \approx 0$ и $b>0$. The use of outsourcing is aimed at reducing the breakeven level of the enterprise. We will call this model "sustainable outsourcing". 
The visually proposed approach to the classification of outsourcing is presented in Figure 4.

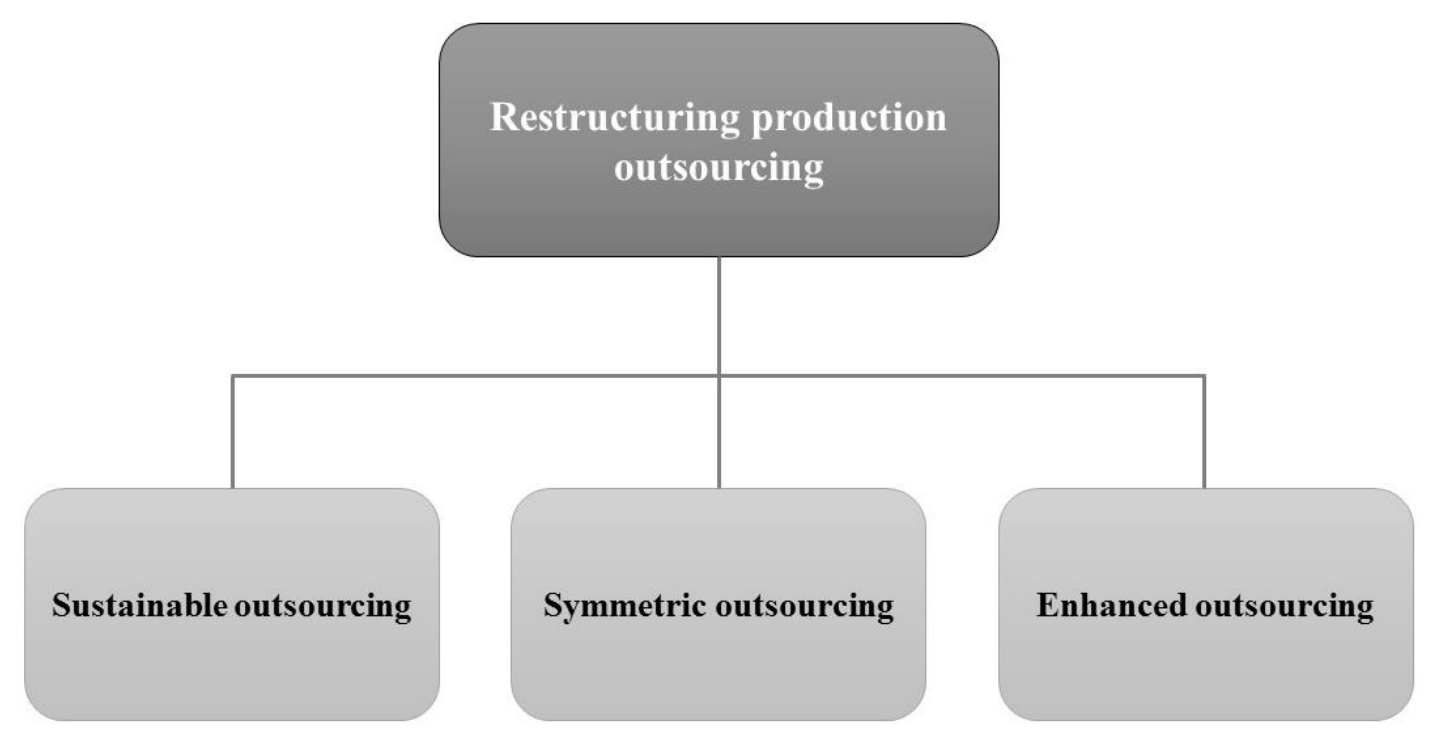

Figure 4. Classifications of restructuring production outsourcing

When a company is incapable of meeting the increased demand at the peak of the economic cycle, that is, $a>0$, and/or has a breakeven level higher than the volume of consumption at the bottom of the economic cycle, that is, $b>$ 0 , then the use of restructuring production outsourcing is advisable.

Next, we consider the methodology for assessing the economic effect of symmetric outsourcing usage.

In accordance with expression (1), the economic effect of the outsourcing utilization to the implementation of restructuring measures is evaluated using expression (2).

$$
\left\{\begin{array}{l}
v_{1}-v_{2}=a \\
v_{3}-v_{4}=b
\end{array}\right.
$$

where $a$ and $b$ are the planned economic effects of restructuring production outsourcing.

After the implementation of restructuring measures, it is necessary to evaluate the achieved production capacity and the breakeven level of the enterprise from the use of outsourcing, and respectively, the actual achieved economic effect is estimated using expression (3).

$$
\left\{\begin{array}{l}
v_{1}-v_{2}^{*}=a^{*} \\
v_{3}^{*}-v_{4}=b^{*}
\end{array}\right.
$$

where $v_{2}^{*}$ - the enterprise's production capacity after outsourcing; $v_{3}^{*}$ - the enterprise's breakeven point after outsourcing; $a^{*}$ и $b^{*}$ - the actual economic benefits of outsourcing.

In this case, an assumption has been made:

$$
\left\{\begin{array}{l}
v_{2}^{*} \leq v_{1} \\
v_{3}^{*} \geq v_{4}
\end{array}\right.
$$

The maximum economic effect from the use of restructuring production outsourcing is achieved when the condition (5).

$$
\left\{\begin{array}{l}
a=a^{*} \\
b=b^{*}
\end{array}\right.
$$

\section{Summary}

The change in production technology in recent decades and the move away from mass production in large industries and the tendency towards flexible production in small and medium industries have increased the competitiveness of 
small industrial activities. This factor has led to the transfer of economic activities from large industries to small industries. But it should be noted that this did not mean eliminating large industries and replacing them with small ones. It should be noted that in many countries, the number of small and medium enterprises affects the GDP more than the number of large enterprises. Among the reasons for the low impact of large enterprises are problems related to financing, providing skilled manpower, raw material price instabilities and macro-space instabilities. Based on the results, it seems that solving the business challenges of small and medium enterprises, as well as large enterprises and appropriate direct or indirect support for enterprises, can have a positive effect on the economic growth of countries.

In recent years, outsourcing, as one of the tools for organizational development and product promotion in the form of downsizing, has been considered by managers and officials of organizations and has been implemented in various ways. It has also gained more and more applications as a simple and economical executive tool. Outsourcing some work outside the organization, like any other method, can be as beneficial as it can be, if it does not have defined and clear terms and standards with a purposeful, coherent, scientific and strategic plan, it can cause a lot of losses. Accordingly, outsourcing will be strategic when aligned with the organization's long-term strategies. It should be noted that the benefits of outsourcing appear after several years, and its positive or negative results will be of particular importance to the organization. Choosing the right processes for outsourcing, especially in organizations with high social and economic sensitivities, is one of the most important issues in outsourcing. In order to strategically determine which parts of the work should be outsourced, an executive plan and method should be developed, taking into account the perspectives, missions and main axes of the organization's achievement.

\section{Conclusions}

In this work, a sufficient number of assumptions were made, based on which approaches were proposed to classify restructuring production outsourcing and assess the feasibility and economic effect of using this type of outsourcing. Further scientific research in this area related to expanding the boundaries of assumptions, modelling the behaviour of the company and changes in the market will allow developing the scientific and practical capabilities of the proposed approaches much more widely. Rather, the trend has been towards more interaction between the two. In such a way that the division of labour between small and large industries is done in such a way that they complement each other instead of competing with each other. In recent years, the importance and role of small and medium enterprises, both in industrialized and developing countries, has been increasing. With the advent of new technologies in production, there have been changes in the methods of production, distribution and organizational structure of enterprises, which has increased the importance of small and medium enterprises.

\section{Acknowledgements}

The work is performed according to the Russian Government Program of Competitive Growth of Kazan Federal University.

\section{References}

Alexander, B., Tatiana, K., \& Svetlana, U. (2013). Formation of industrial clusters using method of virtual enterprises. Procedia Economics and Finance, 5, 68-72.

Ardiana, F. (2020). Success Factors For Small And Medium Industries Based On Creative Industries. Economics Development Analysis Journal, 9(1), 23-38.

Asma, Y., Larbi, B. M., \& Samiha, B. (2017). The role of the dashboard in improving marketing decisions in the Algerian economic firm. International Journal of Business and Administrative Studies, 3(6), 209-216.

Bartlett, W., \& Bukvič, V. (2001). Barriers to SME growth in Slovenia. MOST: Economic Policy in Transitional Economies, 11(2), 177-195.

Belcourt, M. (2006). Outsourcing-The benefits and the risks. Human Resource Management Review, 16(2), 269-279.

Christina, B., Neelufer, A., \& Al Amri, S. (2014). Challenges and barriers encountered by the SMEs owners in Muscat. International Journal of Small Business and Entrepreneurship Research, 2(3), 1-13.

Dunn, S. (1999). Maintenance outsourcing-critical issues. Retrieved from www.plant-maintenance.com/maintenance_articles_outsources. $\mathrm{html}$

Farkhoutdinov, I. I., \& Isavnin, A. G. (2017). Restructuring of Russian enterprises on basis of industrial outsourcing. Astra Salvensis, 2017, 331-337. 
Hamdani, N. A., Herlianti, A. O., \& Amin, A. S. (2019, December). Society 5.0: Feasibilities and challenges of the implementation of fintech in small and medium industries. In Journal of Physics: Conference Series (Vol. 1402, No. 7, p. 077053). IOP Publishing.

Hassanomer, W. K., Aljaaidi, K. S., \& Habtoor, O. S. (2020). Board Quality, Audit Quality and Economic Firm Value: The Case of Manufactured Saudi's Listed Companies. Quality-Access to Success, 21(178).

Isavnin, A. G., \& Farkhoutdinov, I. I. (2012a). Method of economic efficiency evaluation of industrial outsourcing application at Russian automotive enterprise. Journal Regional Economics: theory and practice, 13(224), 16-21.

Isavnin, A. G., \& Farkhoutdinov, I. I. (2012b). Analysis of the main risks of industrial outsourcing in the Russian automotive industry. In Proceedings of the VIII international scientific and practical conference news of advanced science, Sofia, Bulgaria (Vol. 6, pp. 16-20).

Isavnin, A. G., \& Farkhoutdinov, I. I. (2013). Features of application of industrial outsourcing at the Russian automobile building enterprise. LAP LAMBERT Academic Publishing, AV Akademikerverlag GmbH \& Co, KG, Saarbrücken.

Isavnin, A. G., \& Farkhoutdinov, I. I. (2014). Evaluation of economic effect of using the model of sourcing maneuver at an industrial enterprise. Regional economy: theory and practice, 43(370), 45-50.

Jauhari, A., Suzanti, I. O., \& Yunitarini, R. (2020, July). Decision Support System for Determination of Development of Small and Medium Industries Using VIKOR. In Journal of Physics: Conference Series (Vol. 1569, No. 2, p. 022086). IOP Publishing.

Jiangpo, P. (2008). The Credit Guarantee System of Medium-and-small Enterprises Based on Mutual Guarantee. Journal of Financial Research, 2, 75-82.

Kotliarov, I. D. (2012). Risk assessment of cooperation with an outsourcer. Problems of Economics and Management of the Oil and Gas Complex, (11), 34-37.

Kotrlik, J. W. K. J. W., \& Higgins, C. C. H. C. C. (2001). Organizational research: Determining appropriate sample size in survey research appropriate sample size in survey research. Information Technology, Learning, and Performance Journal, 19(1), 43.

Mahmutov, I. I. (2014). Classification of outsourcing based on the approach IDEF0. V mire nauchnyh otkrytij, 1(49), 1072-1083.

Nasution, D. P., \& Lubis, I. (2019). The Development of Demand for Small and Medium Industries in Indonesia. Development, $4(10)$.

Okpala, L. I. (2019). Effect of Accounting Records on Financial Performance of Small and Medium Industries in Nigeria.

Onn, F. C. (1990). Small and Medium Industries in Malaysia: Economic Efficiency. The Developing Economies, $28,2$.

Poncotoyo, W. (2018). Six sigma implementation model based on critical success factors (CSFs) for indonesian small and medium industries. In MATEC Web of Conferences (Vol. 218, p. 04017). EDP Sciences.

Seth, D., Rehman, M. A. A., \& Shrivastava, R. L. (2018). Green manufacturing drivers and their relationships for small and medium (SME) and large industries. Journal of Cleaner Production, 198, 1381-1405.

Simmonds, D., \& Gibson, R. (2008). A model for outsourcing HRD. Journal of European Industrial Training.

Solaimani, S., Heikkilä, M., \& Bouwman, H. (2018). Business model implementation within networked enterprises: A case study on a Finnish pharmaceutical project. European Management Review, 15(1), 79-96.

Szromek, A. R., \& Naramski, M. (2019). A business model in Spa tourism enterprises: case study from Poland. Sustainability, 11(10), 2880.

Tsukerman, V. A., \& Kozlov, A. A. (2018). Outsourcing noncore activities of industrial enterprises in the Arctic zone of the Russian Federation. Studies on Russian Economic Development, 29(3), 252-256.

Visvanathan, C., \& Kumar, S. (1999). Issues for better implementation of cleaner production in Asian small and medium industries. Journal of Cleaner Production, 7(2), 127-134.

Widayani, A., Astuti, E. S., \& Saifi, M. (2020, May). Competence and readiness of small and medium industries against of industrial revolution 4.0. In IOP Conference Series: Earth and Environmental Science (Vol. 485, No. 1, p. 012114). IOP Publishing. 
Wu, L., \& Park, D. (2009). Dynamic outsourcing through process modularization. Business Process Management Journal.

Xu, M., David, J. M., \& Kim, S. H. (2018). The fourth industrial revolution: Opportunities and challenges. International Journal of Financial Research, 9(2), 90-95.

\section{Copyrights}

Copyright for this article is retained by the author(s), with first publication rights granted to the journal.

This is an open-access article distributed under the terms and conditions of the Creative Commons Attribution license (http://creativecommons.org/licenses/by/4.0/). 